\title{
Research on Tourism Development of Zhenlai County Under the Background of Pro-Poor Tourism
}

\author{
Fangfang Wang ${ }^{1, *}$ and Xuefeng Wang ${ }^{1}$ \\ ${ }^{1}$ Tourism Management, School of Economics and Management, Beijing Jiaotong University \\ *Corresponding author. Email: 20120728@bjtu.edu.cn
}

\begin{abstract}
This article is based on the research background of the nation's commitment to poverty alleviation in 2020, combined with relevant domestic and foreign research, and identified Zhenlai County as the research object. After field investigation and SWOT analysis, this paper summarizes the main advantages, disadvantages, opportunities and threats in the development of raitant tourism in towns, and puts forward several optimization Suggestions and countermeasures, which can provide reference for the development of tourism in other underdeveloped areas, so as to consolidate the achievements of poverty alleviation work.
\end{abstract}

Keywords: SWOT analysis, Zhenlai County, Pro-poor tourism, Eco-tourism.

\section{INTRODUCTION}

On March 6, 2020, Xi Jinping participated in a decisive victory over the poverty alleviation symposium and proposed that "all the rural poor under the current standards by 2020 will be lifted out of poverty. This is a solemn promise made by the Party Central Committee to the people of the whole country. It must be achieved as scheduled, without any retreat and flexibility."[1]

Zhenlai County is located in a contiguous destitute area at the southern foot of the Greater Khingan Mountains and is a key area in the national poverty reduction work. Due to the weak agricultural support system, the income of agricultural households is lower and the poor population is larger.[2] The development of tourism is conducive to the protection of ecological resources, sustainable economic development, and all-round social development. With the development of tourism, people's living standards have been improved. This paper summarizes the current situation of tourism development in Zhenlai County, identifies problems and difficulties, and puts forward corresponding solutions and countermeasures, in order to explore a characteristic path suitable for the development of tourism in Zhenlai County and help promote the high-quality development of its tourism industry.

\section{THEORIES AND LITERATURE}

\subsection{Relevant Theories}

\subsubsection{Sustainable Development Theory}

The concept of sustainable development was formally put forward by The Chairman of the United Nations Commission on World and Environmental Development, Brundtland, in his report "Our Common Future" published in 1987. Its core idea is to seek development for our generation without harming the interests of future generations.[3] The United Nations has defined 2017 as the "International Year for Sustainable Tourism Development" to "promote tourism development to make more and greater contribution to global economic, social and environmental sustainable development". The United Nations has stated that sustainable tourism should contribute to global sustainable development in all aspects.[4]

\subsubsection{P Marketing Theory}

The 4P marketing theory, which came into being in the $1960 \mathrm{~s}$, was the first time that the classic $4 \mathrm{P}$ theory in traditional marketing was formally proposed by Jerome McCarthy, a famous American marketer, in his book "Basic Marketing" after summary and analysis. It is a kind of combined marketing strategy.[5] After combining with tourism, the product strategy tourism 
products and tourism service quality to meet the demand of tourists, the pricing strategy requires travel products suppliers pay more attention to the brand value and provide cost-effective products, the place strategy required to provide diversified ways to meet different tourists purchase demand, the promotion strategy requirements keep up with the trend of The Times as much as possible to receive promotional information for visitors.

\subsubsection{Industrial Integration Theory}

Industrial integration refers to the evolution process in which one or more industries merge with another or more industries to form new industrial forms.Tourism, as a tertiary industry, usually integrates with agriculture, forestry, animal husbandry and fishery in the primary industry, and gives rise to new forms of tourism such as rural tourism and forest tourism. Of course, sustainable tourism development cannot be achieved without the cooperation of green development of the secondary industry. Industrial integration can provide innovative ideas for the development of a single industry, help to expand and occupy the market more quickly, and play an important role in promoting the development of tourism.

\subsection{Literature Review}

\subsubsection{Tourism Poverty Alleviation}

As early as the 1960s and 1970s, foreign countries began to pay attention to tourism development to promote poverty reduction [6]. Department for International Development (of the United Kingdom) put forward the concept of PPT (Pro-Poor Tourism) in 1999. Research on poverty alleviation by tourism abroad focused on the impact of the development of tourism on the macroeconomic growth of underdeveloped countries, after 2000, focused on the research on poverty alleviation by tourism for the poor at various micro-levels. [7] Domestic research on poverty alleviation by tourism mainly focused on the development of tourism resources before 2000. Since then, research has gradually turned to the micro-level.[9] Guo Qingxia (2003) pointed out that government support and guidance is indispensable in tourism poverty alleviation. Yang Dejin (2016) explored ways to improve the eco-efficiency of tourism poverty alleviation.

\subsubsection{Eco-tourism}

"Ecological tourism" proposed by Heidr in the 1960s was the bud of eco-tourism. In 1983, Ceballos Lascurain first proposed the Spanish "tourisimo ecologico", which means eco-tourism.[10] Since then, eco-tourism has gradually attracted the attention of scholars from all over the world. Domestic eco-tourism research emerged in the early 1990s. Huang Jihua et al. (2009) believed that the eco-tourism system should be improved. Gao Jun (2016) proposed to improve the overall efficiency of tourism ecology. In recent years, Xi Jinping proposed a series of new national development concepts on the ecological environment, which have had a profound impact on my country's eco-tourism.

\section{ZHENLAI COUNTY DEVELOPMENT BACKGROUND}

\subsection{Overview of Zhenlai County}

Zhenlai County, under the jurisdiction of Baicheng City, Jilin Province, is located at the junction of Jilin, Inner Mongolia, and Heilongjiang. The ethnic cultures are diverse, the terrain is higher in the northwest and flat in the southeast, temperate continental monsoon climate is typical, "one river and three watercourses" (Nenjiang, Taoerhe, Huerdahe, Erlongtaohe) flow through, biological resources are rich, etc.

\subsection{Overview of Tourism Resources in Zhenlai County}

Wetland ecosystem has high-quality natural surface water resources; the rest time and population number of the Grus leucogeranus in Momoge National Nature Reserve are the highest in the world. Zhenlai County has the honorary title of "Hometown of the Grus leucogeranus in China"; tourist catering and the accommodation industry can meet the current development needs of tourism.

Its representative tourism resources include Momoge National Nature Reserve, Nanhu Ecological Park, Xiangyang Nangangzi Site, etc.

In 2018, it received 320,000 tourists (times) and realized a total tourism income of 270 million yuan. In 2019 , it received 580,000 tourists (times) and realized a total tourism income of 480 million yuan.

\section{SWOT ANALYSIS OF TOURISM DEVELOPMENT IN ZHENLAI COUNTY}

\subsection{Main Strengths}

Tourism resources are rich. The county has Momoge National Nature Reserve (a national 4A-level tourist attraction), rich artificial wetland resources, Nanhu Ecological Park, etc., which have a good foundation for the development of the eco-tourism industry. Zhenlai County is an important stop for migratory birds in East Asia. A large number of rare migratory birds stop here in spring and autumn every year. 
Policy support is strong. The "Northeast Region Tourism Development Plan" jointly issued by the People's Republic of China National Tourism Administration and the National Development and Reform Commission has raised the development of the tourism industry in the Northeast region to the national level. According to the "Master Plan for Tourism Development of Zhenlai County", the development focus is on eco-tourism, and the purpose of development is to build a large wetland eco-tourism county. In response to relevant poverty alleviation policies, by 2019 Zhenlai County has developed more than 10 rural tourism poverty alleviation farmhouses, with a total of 500 beds and more than 1,000 tourism employees, including more than 800 poor people.

Brand advantage is outstanding. There are 6 species of cranes in the Momoge Reserve in Zhenlai County, and the Grus leucogeranus is the first-level key protected animal in my country. There are more than 3,500 in the world, and it is also the flagship species of the protected objects in the Momoge Reserve in Zhenlai County. The scarcity and uniqueness of this brand have greatly improved the visibility and influence of the development of tourism in Zhenlai.

\subsection{Main Weaknesses}

The infrastructure is backward. Zhenlai County was once a national-level poor county. It has been out of poverty for more than a year, and the tourist infrastructure in various scenic spots is relatively backward. For example, the nature museum in the Momoge Reserve is not well maintained, and many specimens are not updated in time or damaged, resulting in a poor experience for tourists; there is a lack of indication signs and safety signs in the wetland ecological scenic spot. The population density of the scenic spot is low, and the public service conditions such as medical and health cannot keep up with the demand of tourists.

Project development has limitations. The protective nature of the characteristic tourism resources of Zhenlai County has led to limitations in the development of tourism projects. The protection area first considers reasonable and effective protection of the ecological environment. At present, it mainly develops sightseeing tourism with the low participation of tourists.

The location and climatic conditions are poor. Baicheng Airport is still under construction. Tourists need to change to various modes of transportation when entering and leaving Zhenlai County. There is also a lack of special transportation such as tourist buses between various scenic spots in the country. In winter, the snow accumulates for a long time, and the snowfall and low-temperature cause traffic restrictions and are not conducive to people's travel.

\subsection{Main Opportunities}

The eco-tourism market is vast. With the rapid economic development and the acceleration of urbanization, China is entering the era of mass leisure, and tourism and leisure have become a new bright spot in national life. The rare migratory birds in spring and autumn attract a large number of students or experts and scholars to study here. The rich aquatic products and natural green vegetables in summer attract food lovers to feast and avoid the heat and enjoy the cool. In winter, take advantage of Harzhuo winter catching activities to welcome snow and ice travel lovers.

The policy environment is good. The "Government Work Report" issued by Zhenlai County stated that "We must give full play to the geographical advantages at the junction of the three provinces and regions, fully tap the tourism market, focus on promoting the construction of national rural tourism demonstration villages, strive to create national tourism demonstration counties, and comprehensively improve China The popularity and influence of ' Hometown of the Grus leucogeranus in China '." The " the 13th Five-Year Plan" also clearly stated that the development of ecological tourism should be accelerated to achieve sustainable, healthy and rapid development of the tourism industry.

\subsection{Main Threats}

The problem of ecological environment protection is severe. Since its establishment in 1981, Momoge National Nature Reserve has had some ecological problems, such as the reduction of wetland area directly caused by oil exploitation in the area, and the survival of rare birds such as cranes and storks are seriously threatened; the regional temperature has risen in recent years, and precipitation has decreased. , Bring a great threat to the wetland environment, etc. The development of eco-tourism in Zhenlai County should follow the principle of protection first, and solve the environmental problems that arise during development.

Competition for similar products makes market expansion difficult. Zhenlai County is located in the fusion zone of Horqin Grassland and Songnen Plain. The surrounding counties and cities have similar grassland tourism resources; in terms of eco-tourism, the adjacent Tumuji National Nature Reserve and Erlongtao Reserve are also attractive, these will divert its source market. Zhenlai County's high-grade tourism resources have not yet been transformed into product advantages. Tourism companies present a status quo of "scattered, small, weak, and poor". They have not established their uniqueness among the many eco-tourism areas and have a single source of tourists. 


\section{SUGGESTED COUNTERMEASURES FOR THE DEVELOPMENT OF TOURISM IN ZHENLAI COUNTY}

\subsection{Strengthen Infrastructure Construction and Improve Service Quality}

In developing, the government should attach great importance to the development of the tourism industry and increase the development of tourism resources and the construction of tourism infrastructure. The types and grades of accommodation should be increased for tourists to choose. The construction of tourist roads should be strengthened, tourist buses or sightseeing cars should be added between scenic spots, and tourist trails and recreational facilities should be added in scenic spots. The tourism surroundings should be innovatively designed, such as white crane dolls, wetland landscape paintings, fish and shrimp snacks, etc., and original protection should be carried out to increase tourism highlights and increase tourism income. It is necessary to combine unique folk customs and ecological environment to build famous brand entertainment facilities and increase scenic spots.

It is necessary to enhance service awareness, train relevant practitioners, and comprehensively improve service quality. It is necessary to follow the development of the times to improve and innovate the tourism service system, and enhance the standardization, standardization and branding of services. The opinions of tourists are solicited through questionnaires, inquiries and other methods. The authentic and reliable service quality evaluation results provided by tourists will help promote service companies to implement quality improvement measures and provide accurate and meticulous services according to the immediate needs of tourists.

\subsection{Increase Investment in the Tourism Industry}

It is necessary to build a diversified investment pattern, integrate tourism resources, tap the connotation of tourism culture, develop characteristic tourism industries according to local conditions, and promote the better development of the county's tourism industry. We should actively attract foreign investment and strengthen the construction of scenic spots. It is necessary to complete the work goals of wetland ecotourism counties, gradually improve the construction of rural tourism projects such as Yangsha Lake Tourist Resort Scenic Area, Jinfeng Tourist Resort Resort, and relevant departments to increase investment in ecotourism to make the tourism industry more effectively and orderly, healthy growth.

\subsection{Multi-Channel Integrated Distribution}

It is necessary to build a smart tourism omni-media marketing platform and a smart scenic spot service platform in Zhenlai County with the integration and application innovation of information technology as the center, and establish a new intelligent tourism economic development model. Tourism products should be sold through online platforms such as Taobao and Weidian, and relevant information should be pushed through Weibo and WeChat official accounts, and short video self-media platforms such as Douyin and Kuaishou should be used to shoot micro-videos to establish the tourism image of the town. Elderly tourists are not proficient in using the Internet. They need to contact travel information through traditional channels such as television, newspapers and periodicals, and purchase travel products offline through travel agencies. We must actively use traditional channels to hold various offline activities to attract more tourists' attention.

\subsection{Carry out Special Publicity and Build Brand Image}

A team should be formed or outsourced to a professional propaganda team to push the most timely and complete information of Zhenlai tourist attractions to provide tourists with new travel options. We can enrich the connotation of Zhenlai's tourism culture by searching for historical materials, collecting folklore, and sorting out vivid and legendary stories. It is necessary to create a personalized network publicity method for the town, maintain the spirit of innovation, and integrate eco-tourism resources with popular science activities. The Australian government stipulates that primary and secondary schools should conduct environmental protection learning in the reserve every year. We can learn from its experience and carry out environmental education activities to attract students to come here to study. It is necessary to create tourist activities with high participation and high experience of tourists, pay attention to brand value, work hard to maintain the brand, and increase visibility and influence.

\section{CONCLUSION}

Based on a field visit to Zhenlai County, this article consulted a large amount of information, combined with national current affairs hotspots and local development status, used SWOT and other analysis methods, and reached the following conclusions:

(1) Zhenlai County has unique eco-tourism resources and a relatively broad market. Vigorously developing eco-tourism is of great significance both in terms of economic development and ecological protection.

(2) Its tourism development has great advantages, but there are also some disadvantages. Therefore, it is 
necessary to actively learn and draw on the advanced experience of domestic and foreign tourism development, and strive to seize favorable opportunities and avoid external and internal threats.

(3) 2020 is a year of a decisive victory for poverty alleviation. Zhenlai, as a district and county that has just been alleviated from poverty, is the focus of poverty alleviation. Active development of tourism can drive the employment of the poor, increase income, promote economic development, and consolidate the achievements of poverty alleviation work.

\section{REFERENCES}

[1] Xi Jinping. Speech at the Symposium on Decisive Victory of Poverty Alleviation [N]. People's Daily, 2020-03-07 (002). (in Chinese).

[2] Wang Youjian. Problems in the Poverty Alleviation and Development of Financial Services in Contiguous and Destitute Areas and Related Suggestions: Taking the Concentrated Contiguous and Destitute Baicheng Area at the Southern Foot of the Greater Xing'an Mountains as an Example $[\mathrm{J}]$.

[3] Jilin Financial Research, 2014(07): 48- 50+73. (in Chinese).
[4] Lian Huang.A Study on Countermeasures for the Development of Marine Eco-tourism in Sanya [D]. Sanya: Hainan Institute of Tropical Oceanography, 2019. (in Chinese).

[5] Song Rui.Research on Sustainable Tourism Development in the Context of Ecological Civilization System Construction [J]. Ecological Economy, 2008, 34(09): 134-138. (in Chinese).

[6] Karina Kusuma Halim, Siana Halim, Felecia. Business Intelligence for Designing Restaurant Marketing Strategy: A Case Study [J]. Procedia Computer Science, 2019, 161.

[7] David Harrison. Pro-poor Tourism: A Critique [J]. Third World Quarterly, 2008, 29(5).

[8] Huang Yuanji. Research on Poverty Alleviation by Tourism in Ethnic Minority Regions [D]. Changsha: Hunan Agricultural University, 2017. (in Chinese).

[9] Wan Qing, Fan Qiaoxi. Overview of Research on Poverty Alleviation by Tourism at Home and Abroad [J]. Rural Economy and Technology, 2019, 30(23): 122-126. (in Chinese).

[10] Han Meng. A review of Eco-tourism Development Research [J]. Green Science and Technology, 2017(17): 200-203. (in Chinese). 